Revista Brasileira de Agricultura Irrigada v.11, nº.6, p. 1784 - 1796, 2017

ISSN 1982-7679 (On-line)

Fortaleza, CE, INOVAGRI - http://www.inovagri.org.br

DOI: $10.7127 /$ rbai.v11n600579

Protocolo 579.17 - 20/02/2017 Aprovado em 18/07/2017

\title{
DESENVOLVIMENTO DO TOMATEIRO IRRIGADO COM ÁGUA RESIDUÁRIA DE SUINOCULTURA
}

\author{
Daniely Karen Matias Alves ${ }^{1}$, Rannaiany Teixeira Manso², Marconi Batista Teixeira ${ }^{3}$, \\ Fernando Nobre Cunha ${ }^{4}$, Frederico Antonio Loureiro Soares ${ }^{5}$, Fernando Rodrigues Cabral \\ Filho $^{6}$
}

\section{RESUMO}

O uso das águas residuárias da suinocultura pode se tornar uma alternativa importante como forma de redução de custos de produção, no que concerne à fertilização das plantas. O objetivo desse trabalho foi avaliar o desenvolvimento e o índice SPAD do tomate (variedade Santa Clara) com água residuária de suinocultura. O delineamento experimental utilizado foi o inteiramente casualizado, analisado em esquema de parcela subdividida (5 x 4), com dez repetições. Os tratamentos foram: água residuária bruta; água residuária filtrada em filtro de areia; água SODIS (Solar disinfection); $50 \%$ da água residuária filtrada e 50\% com água SODIS; água de abastecimento (testemunha) e quatro épocas de avaliações 60, 80, 100 e 120 dias após o plantio. A água residuária utilizada foi coletada na granja de suinocultura do IFGoiano - Campus Rio Verde e devidamente transportada em recipientes de $100 \mathrm{~L}$ para o local de execução do experimento. A lâmina aplicada foi determinada de acordo com a parcela de evaporação de água no solo contido nos lisímetros de pesagem, sendo que cada lisímetro foi submetido a 100\% da reposição hídrica (RH) quando da capacidade de água disponível no solo (CAD). A maior área foliar em tomate foi encontrada aos 120 dias após o plantio, sendo esta de até $57 \%$ maior do que os observados aos 60 dias após o plantio, para os tipos de água. O índice SPAD do tomate submetido a aplicação de água residuária bruta de suinocultura demonstra um incremento de até 31\%.

Palavras-chave: Solanum lycopersicum, lisímetro, área foliar.

\section{DEVELOPMENT OF IRRIGATED TOMATO WITH SWINE WASTEWATER}

\footnotetext{
${ }^{1}$ Graduanda em Engenharia Ambiental, Instituto Federal Goiano - Campus Rio Verde, Rodovia Sul Goiana, Km 01, CEP: 75.901-170, Rio Verde - GO, e-mail: daniely_karen@hotmail.com

${ }^{2}$ Graduanda em Engenharia Ambiental, IFGoiano - Campus Rio Verde, e-mail: rannaiany@hotmail.com ${ }^{3}$ Eng. Agrônomo, Prof. Dr. em Agronomia, IFGoiano - Campus Rio Verde, e-mail: marconibt@gmail.com ${ }^{4}$ Doutorando em Ciências Agrárias - Agronomia, IFGoiano - Campus Rio Verde, e-mail: fernandonobrecunha@hotmail.com

${ }^{5}$ Eng. Agrônomo, Prof. Dr. em Agronomia, IFGoiano - Campus Rio Verde, e-mail: fredalsoares@hotmail.com ${ }^{6}$ Graduando em Agronomia, IFGoiano - Campus Rio Verde, e-mail: fernandorcfilho10@gmail.com
} 


\begin{abstract}
The use of wastewater from swine farming can become an important alternative as a way of reducing production costs, with regard the fertilization of plant. The objective of this work was to evaluate the development and SPAD index of tomato (Santa Clara variety) with swine wastewater. The experimental design was completely randomized, in a subdivided plot scheme (5 x 4), with ten replications. The treatments were: raw waste water, filtered waste water, SODIS (Solar disinfection) water, 50\% filtered wastewater and 50\% SODIS water; water supply (control) and four evaluation periods 60, 80, 100 and 120 DAP (days after planting). The used wastewater was collected at the IFGoiano - Campus Rio Verde and duly transported in $100 \mathrm{~L}$ containers to the local of experiment. The applied water was determined according with the evaporation of water in the soil contained in the weighing lysimeters, and each lysimeter was submitted to $100 \%$ of the water replacement (RH) when the available water capacity in the soil (AWC). The largest leaf area in tomato found at 120 days after planting, which was up to $57 \%$ higher than those observed at 60 days after planting, for water types. The SPAD index of the tomato submitted to the application of swine wastewater demonstrates an increase of up to $31 \%$.
\end{abstract}

Keywords: Solanum lycopersicum, lysimeters, leaf area.

\section{INTRODUÇÃO}

A suinocultura é uma atividade que apresenta grande potencial poluidor para o meio ambiente e de acordo com Souza et al. (2010), uma das alternativas encontradas para minimizar esse problema é a utilização da água residuária gerada pela suinocultura para fins agrícolas, de forma a trazer benefícios tanto para o agricultor quanto para o meio ambiente.

A cultura do tomate é uma das mais exigentes por tecnologias específicas, com custos de produção elevados em função de maior necessidade de fertilizantes e agroquímicos (AGRIANUAL, 2009). Assim, o uso das águas residuárias da suinocultura pode se tornar uma alternativa importante como forma de redução de custos de produção, no que concerne à fertilização das plantas (SOUZA, 2010), minimizando os impactos ambientais e trazendo incremento na produtividade.

Segundo Porto (2014) para avaliar o potencial de produção das culturas frequentemente são utilizados parâmetros como diâmetro da haste principal e a altura para verificar as respostas das plantas ao tratamento. Para Reis et al. (2013b) a área foliar também é de suma importância para modelar o crescimento e desenvolvimento das plantas. Ferreira et al. (2006) constatou aumentos nos teores de clorofila total e, ou, valores de índice SPAD nas folhas das plantas de tomate, consequentemente a avaliação do crescimento, desenvolvimento e do índice SPAD representa um método para verificação da produção e do potencial de biomassa vegetal, muito importante para a caracterização da cultura do tomate quando submetida a diversas situações e até mesmo quando sob a aplicação de água residuária de suinocultura (PORTO, 2014).

Nesse contexto, o objetivo desse trabalho foi avaliar o desenvolvimento e o índice SPAD do tomate (variedade Santa Clara) com água residuária de suinocultura.

\section{MATERIAL E MÉTODOS}

O experimento foi realizado em casa de vegetação climatizada no Instituto Federal Goiano - Campus Rio Verde, no Sudoeste de Goiás. A temperatura média foi de $27^{\circ} \mathrm{C} \pm 3$, a umidade relativa média foi de $70 \% \pm 3$ e a velocidade do vento foi de $2,4 \mathrm{~km} \mathrm{~h}^{-1}$ quando o ventilador exaustor estava em movimento. O solo utilizado foi classificado como 
Latossolo Vermelho distroférrico (LVdf), de textura média (EMBRAPA, 2013). As características químicas do solo estão apresentadas na Tabela 1.

Tabela 1. Características químicas do solo da área experimental

\begin{tabular}{|c|c|c|c|c|c|c|c|c|c|}
\hline & \multicolumn{9}{|c|}{ Características químicas $^{1}$} \\
\hline Prof. & $\mathrm{N}$ & $\mathrm{P}$ & K & $\mathrm{Ca}$ & $\mathrm{Mg}$ & $\mathrm{S}$ & $\mathrm{Al}$ & $\mathrm{H}+\mathrm{Al}$ & $\mathrm{pH}$ \\
\hline $\mathrm{m}$ & $\%$ & \multicolumn{2}{|c|}{$\mathrm{mg} \mathrm{dm} \mathrm{dm}^{-3}$} & \multicolumn{2}{|c|}{ cmolc $\mathrm{dm}^{-3}$} & $m g \mathrm{dm}^{-3}$ & \multicolumn{2}{|c|}{ cmolc dm ${ }^{-3}$} & $\mathrm{CaCl}_{2}$ \\
\hline $0,00-0,20$ & & 0,19 & 42,0 & 2,82 & 0,97 & 4,55 & 0,00 & 1,78 & 6,0 \\
\hline Prof. & $\mathrm{Na}$ & $\mathrm{Zn}$ & $\mathrm{B}$ & $\mathrm{Cu}$ & $\mathrm{Fe}$ & $\mathrm{Mn}$ & M.O & CTC & $\mathrm{V}$ \\
\hline $\mathrm{m}$ & \multicolumn{6}{|c|}{$\mathrm{mg} \mathrm{dm}^{-3}$} & $\mathrm{~g} \mathrm{dm}^{-3}$ & \multicolumn{2}{|c|}{$\%$} \\
\hline $0,00-0,20$ & 0,00 & 1,23 & 0,07 & 1,97 & 37,54 & 40,65 & 24,9 & 5,68 & 68,7 \\
\hline
\end{tabular}

${ }^{1}$ Profundidade (Prof); Extrator de P e K, Mehlich ${ }^{-1}$; Matéria Orgânica (M.O); Capacidade de troca de cátions (CTC); Porcentagem de saturação de bases (V).

A casa de vegetação utilizada possui o sistema de climatização (temperatura e umidade) por circulação e refrigeração de água, aeração controlada por exaustores e cortina de sombreamento. A água residuária utilizada foi coletada na granja de suinocultura do IFGoiano - Campus Rio Verde, devidamente transportada em recipientes de $100 \mathrm{~L}$ para o local de execução do experimento, onde foi submetida ao processo de filtragem, através de um filtro constituído com várias camadas de areia e brita e também ao processo de desinfecção solar (SODIS: solar desinfection).

O delineamento experimental utilizado foi o inteiramente casualizado, analisado em esquema de parcela subdividida ( $5 \times 4$ ), com dez repetições. Os tratamentos foram: água residuária bruta (ARB); água residuária filtrada em filtro de areia (ARF); água SODIS (Solar disinfection) (ARS); 50\% da água residuária filtrada e 50\% com água SODIS (ARFS); água de abastecimento (testemunha) (AA) e quatro épocas de avaliações 60, 80, 100 e 120 dias após o plantio (DAP). As mudas de tomate (variedade Santa Clara) foram transplantadas para vasos de $20 \mathrm{~L}$ aos 25 dias após o plantio, quando houve a formação de cinco folhas definitivas da muda de tomateiro.

Para esse estudo foram usados 4 lisímetros de pesagem com célula de carga construídos de chapa metálica galvanizada com espessura de $2 \mathrm{~mm}$ com dreno constituído de tubo PVC de 3/4" e válvula de abertura na parte inferior. Os lisímetros foram dispostos em paralelo entre si, sendo que as unidades da extremidade possuem dimensões de $0,80 \mathrm{~m}$ de diâmetro por 0,75 de altura e os 2 centrais $0,70 \mathrm{~m}$ de diâmetro e mesma altura dos demais, cujas áreas correspondem a 0,503 e $0,385 \quad \mathrm{~m}^{2}$ respectivamente. $\mathrm{O}$ sistema de armazenamento de dados é composto de um "data logger" conectado ao módulo indicador de pesagem de cada lisímetro, onde foi programado para armazenar as variações de massa e desvios-padrões no sistema em intervalos de 15, 30 e 60 min. A lâmina aplicada foi determinada de acordo com a parcela de evaporação de água no solo contido nos lisímetros de pesagem, sendo que cada lisímetro foi submetido a $100 \%$ da reposição hídrica (RH) quando da capacidade de água disponível no solo (CAD).

As variáveis avaliadas foram: a altura de planta (AP), diâmetro do caule (DC), comprimento da folha (CF), largura da folha (LF), área foliar (AF) e o índice SPAD do tomate. A altura de planta (AP) foi obtida com o auxílio de uma trena métrica, medindo-se a distância entre o nível do solo e a gema apical. O diâmetro de caule (DC) foi mensurado próximo a superfície do solo, com auxílio de paquímetro digital eletrônico do tipo "bico fino" (Ponta Aguda) com precisão de $0,01 \mathrm{~mm}$.

O comprimento da folha (CF) foi determinado com o auxílio de uma régua, medindo-se a distância entre o ponto de inserção do pecíolo no limbo foliar e a extremidade oposta da folha e a largura (LF) foi obtida medindo-se a maior dimensão da folha perpendicular ao eixo do comprimento. 
A área foliar da cultura foi medida pela metodologia desenvolvida por Blanco (1999). Utilizou-se o medidor portátil SPAD502 (SPAD) para determinar o índice SPAD. As medições foram realizadas em cinco folíolos de cada folha, sendo dois de cada lado da folha (laterais), e no folíolo terminal central.

Os dados obtidos foram submetidos à análise de variância pelo teste $\mathrm{F}$ e em caso de significância foi realizada análise de regressão para os dias após o plantio e as médias dos tipos de águas foram comparadas entre si pelo teste Tukey a 5\% de probabilidade. Os dados para cada variável foram submetidos à análise de variância pelo programa estatístico SISVAR
(FERREIRA, 2011).

\section{RESULTADOS E DISCUSSÃO}

No resumo da análise de variância, observa-se que houve interação significativa ao nível de $1 \%$ de probabilidade entre os tipos de águas (TAG) e dias após o plantio (DAP) para as variáveis altura de planta, diâmetro de caule, comprimento de folhas, largura de folhas, área foliar e índice SPAD. O coeficiente de variação das variáveis foi no máximo de 11,57\% (Tabela 2). Souza (2010) trabalhando com água residuária também verificou efeito significativo a $1 \%$ para as variáveis de crescimento aos 14 e 28 DAT.

Tabela 2. Resumo da análise de variância para altura de planta (AP), diâmetro de caule (DC), comprimento de folhas (NF), largura de folhas (LF), área foliar (AF) e índice SPAD do tomate.

\begin{tabular}{cccccccc}
\hline \multirow{2}{*}{ FV } & \multirow{2}{*}{ GL } & \multicolumn{7}{c}{ QM $^{1}$} \\
\cline { 3 - 7 } & & AP & DC & CF & LF & AF & SPAD \\
\hline TAG & 4 & $0,38^{* *}$ & $5,93^{* *}$ & $36,75^{* *}$ & $19,65^{* *}$ & $8,14^{* *}$ & $1197,22^{* *}$ \\
Resíduo (a) & 36 & 0,01 & 0,68 & 0,97 & 0,19 & 0,11 & 0,16 \\
DAP & 3 & $13,20^{* *}$ & $45,37^{* *}$ & $69,32^{* *}$ & $29,44^{* *}$ & $14,68^{* *}$ & $0,34^{\text {ns }}$ \\
TAG *DAP & 12 & $0,09^{* *}$ & $0,99^{* *}$ & $1,81^{* *}$ & $1,67^{* *}$ & $0,53^{* *}$ & $22,47^{* *}$ \\
Resíduo (b) & 144 & 0,01 & 0,36 & 0,74 & 0,15 & 0,07 & 0,18 \\
\hline CV a (\%) & - & 8,69 & 9,11 & 7,02 & 6,37 & 11,57 & 0,83 \\
CV b (\%) & - & 9,14 & 6,65 & 6,15 & 5,68 & 9,20 & 0,91 \\
\hline
\end{tabular}

${ }^{1}$ Tipos de águas (TAG), Dias após o plantio (DAP); Coeficiente de variação (CV). ${ }^{* *}$ e ${ }^{*}$ significativo a 1 e $5 \%$ de probabilidade, respectivamente, ${ }^{\text {ns }}$ não significativo pelo teste $\mathrm{F}$ a $5 \%$ de probabilidade.

A altura de planta em função dos dias após o plantio para o tomate se adequou a um modelo linear com $\mathrm{R}^{2}$ de no mínimo 93,55\% (Figura 1). A maior altura de planta em tomate foi encontrada aos 120 dias após o plantio, sendo este 65,9; 62,17; 66,99; 58,28 e $57,59 \%$ maior do que os observados aos 60 dias após o plantio, para os tipos de água residuária bruta, filtrada, SODIS, $50 \%$ filtrada 50\% SODIS e de abastecimento, respectivamente. 


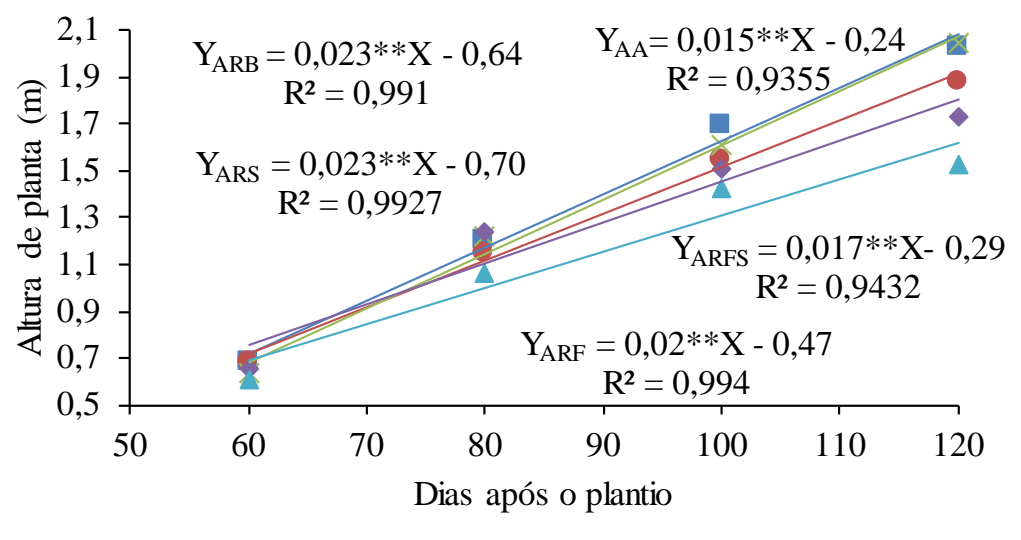

$\square \mathrm{ARB} \odot \mathrm{ARF} \times \mathrm{ARS} \diamond \mathrm{ARFS} \triangle \mathrm{AA}$

${ }^{* *} \mathrm{e}$ * significativo respectivamente a $(\mathrm{p}<0,01$ e 0,05$)$ segundo teste $\mathrm{F}$.

Figura 1. Altura de planta em função dos dias após o plantio para o tomate irrigado com água residuária bruta (ARB), água residuária filtrada (ARF), água residuária SODIS (ARS), água residuária $50 \%$ filtrada $50 \%$ SODIS (ARFS) e água de abastecimento (AA).

Conforme a equação de regressão observou-se um acréscimo na altura de planta de 21,69; 20,72; 22,33; 19,42 e 19,23\% para cada aumento de 20 dias após o plantio para os tipos de água residuária bruta, filtrada, SODIS, $50 \%$ filtrada 50\% SODIS e de abastecimento, respectivamente (Figura 1). Júnior (2014) também constatou que o comprimento médio de plantas foi influenciado positivamente pela concentração nutricional obtida com a aplicação de água residuária ao longo dos dias. Os resultados indicam que a ARS disponibiliza nutrientes para o desenvolvimento da planta (SOUZA et al., 2016).

O diâmetro de caule em função dos dias após o plantio para o tomate se adequou a um modelo linear com $\mathrm{R}^{2}$ variando de 89,08 a 99,72\% (Figura 2). Brito et al. (2014) observou que o diâmetro possui função importante por armazenar sólidos solúveis que podem ser utilizados posteriormente pelas plantas, em virtude disso, o aumento do diâmetro proporcionado pela aplicação de água residuária pode ser indicativo de aumento de produtividade.

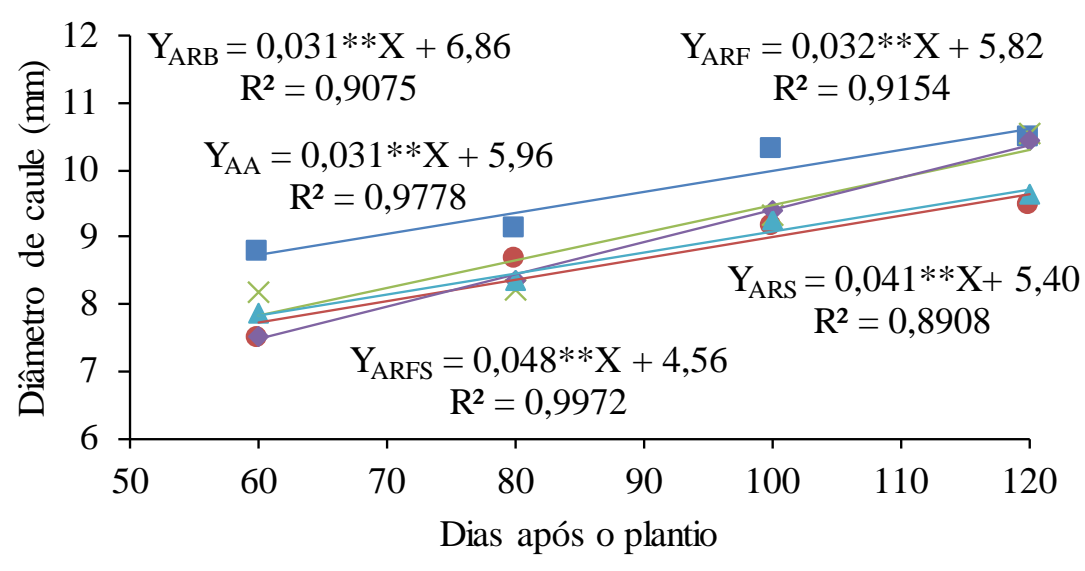

aRB $\odot \mathrm{ARF} \times \mathrm{ARS} \bullet \mathrm{ARFS} \triangle \mathrm{AA}$

${ }^{* *} \mathrm{e}^{*}$ significativo respectivamente a $(\mathrm{p}<0,01$ e 0,05$)$ segundo teste $\mathrm{F}$.

Figura 2. Diâmetro de caule em função dos dias após o plantio para o tomate irrigado com água residuária bruta (ARB), água residuária filtrada (ARF), água residuária SODIS (ARS), água residuária 50\% filtrada $50 \%$ SODIS (ARFS) e água de abastecimento (AA). 
O maior diâmetro de caule em tomate foi encontrado aos 120 dias após o plantio, sendo este 17,58; 50,0; 17,58; 19,79 e $23,75 \%$ maior do que os observados aos 60 dias após o plantio, para os tipos de água residuária bruta, filtrada, SODIS, 50\% filtrada 50\% SODIS e de abastecimento, respectivamente; consequentemente, de acordo com a equação de regressão obteve o acréscimo de 5,86; 16,66; 5,86; 6,59 e 7,91\% para cada aumento de 20 dias após o plantio para os tipos de água residuária bruta, filtrada, SODIS, 50\% filtrada 50\% SODIS e de abastecimento, respectivamente. Corroborando com os resultados desse estudo, Souza (2010) trabalhando com água residuária constatou um incremento no diâmetro de caule em relação aos dias após o transplantio, um fator resultante da disponibilidade de nutrientes para as plantas, em especial o nitrogênio que está presente nas águas residuárias.

O comprimento de folhas em função dos dias após o plantio para o tomate se adequou a um modelo linear com $\mathrm{R}^{2}$ superior a 90\% (Figura 3). Fonseca et al. (2014) também observou que o comprimento de folhas respondeu de forma linear em função dos dias após o plantio.

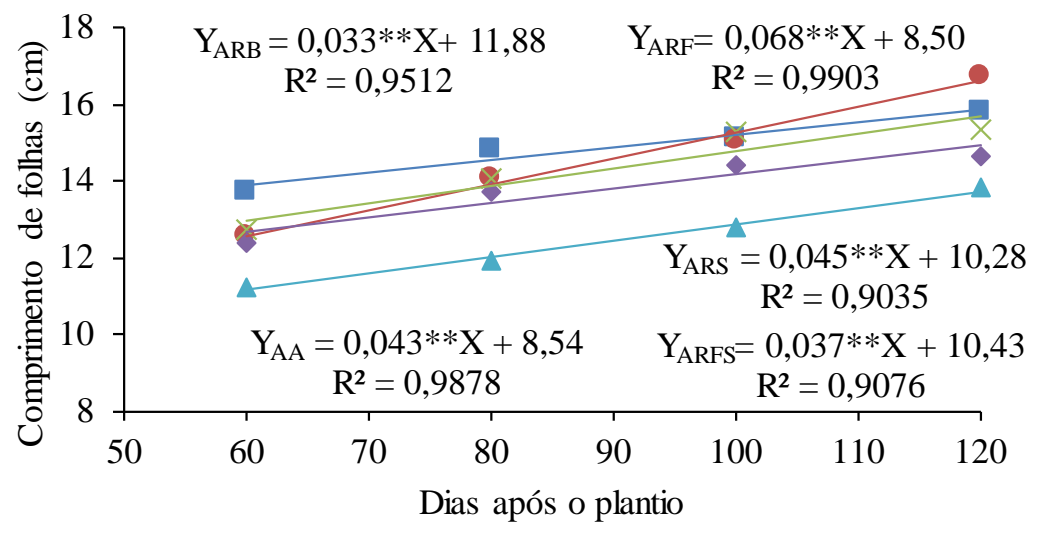

aRB $\bullet \mathrm{ARF} \times \mathrm{ARS} \diamond \mathrm{ARFS} \triangle \mathrm{AA}$

${ }^{* *} \mathrm{e}$ * significativo respectivamente a $(\mathrm{p}<0,01$ e 0,05$)$ segundo teste $\mathrm{F}$.

Figura 3. Comprimento de folhas em função dos dias após o plantio para o tomate irrigado com água residuária bruta (ARB), água residuária filtrada (ARF), água residuária SODIS (ARS), água residuária 50\% filtrada 50\% SODIS (ARFS) e água de abastecimento (AA).

O maior comprimento de folhas em tomate foi encontrado aos 120 dias após o plantio, sendo este 50,0; 12,49; 24,45;17,27; e $15,01 \%$ maior do que os observados aos 60 dias após o plantio, para os tipos de água residuária bruta, filtrada, SODIS, 50\% filtrada 50\% SODIS e de abastecimento, respectivamente; consequentemente, de acordo com a equação de regressão obteve o acréscimo de 16,$66 ; 4,16 ; 8,15 ; 5,75$ e 5,0\% para cada aumento de 20 dias após o plantio para os tipos de água residuária bruta, filtrada, SODIS, 50\% filtrada 50\% SODIS e de abastecimento, respectivamente. O comprimento de folha ao longo do ciclo da cultura é caracterizado por elevado crescimento inicial, seguido de um acréscimo gradual até o período final de avaliação, sendo observados incrementos de $11 \%$ no comprimento de folha, para cada aumento de 30 dias após o plantio (SILVA et al., 2014).

A largura de folhas em função dos dias após o plantio para o tomate se adequou a um modelo linear com $\mathrm{R}^{2}$ de no mínimo 85,22\% (Figura 4). O comprimento de folha, largura de folha, número de folha e área foliar são medidas que permitem avaliar a produtividade da cultura, pois estimam a superfície fotossinteticamente ativa (SILVA et al., 2014). 


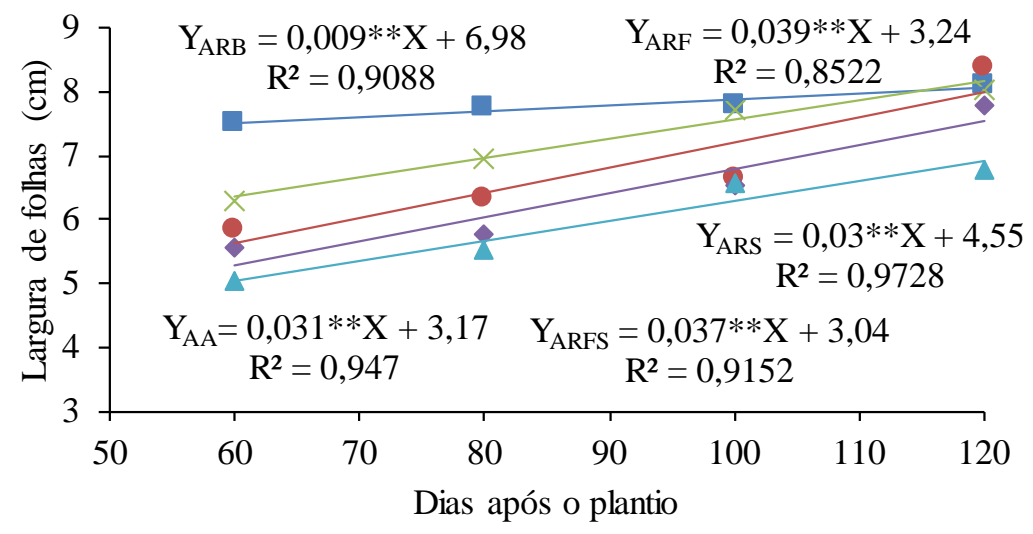

- ARB $\bullet \mathrm{ARF} \times \mathrm{ARS} \bullet \mathrm{ARFS} \triangle \mathrm{AA}$

** $\mathrm{e}^{*}$ significativo respectivamente a $(\mathrm{p}<0,01$ e 0,05$)$ segundo teste $\mathrm{F}$.

Figura 4. Largura de folhas em função dos dias após o plantio para o tomate irrigado com água residuária bruta (ARB), água residuária filtrada (ARF), água residuária SODIS (ARS), água residuária 50\% filtrada $50 \%$ SODIS (ARFS) e água de abastecimento (AA).

A maior largura de folhas em tomate foi encontrada aos 120 dias após o plantio, sendo este 50,$0 ; 6,63 ; 29,73 ; 22,08$ e $29,84 \%$ maior do que os observados aos 60 dias após o plantio, para os tipos de água residuária bruta, filtrada, SODIS, 50\% filtrada 50\% SODIS e de abastecimento, respectivamente; consequentemente, de acordo com a equação de regressão obteve o acréscimo de 16,66; 2,21; 9,91; 7,36 e 9,94\% para cada aumento de 20 dias após o plantio para os tipos de água residuária bruta, filtrada, SODIS, 50\% filtrada $50 \%$ SODIS e de abastecimento, respectivamente (Figura 4). Resultados semelhantes foram obtidos por Galzerano et al. (2012) onde foi verificado que as equações apresentaram maior coeficiente de determinação para a largura quando comparado com o comprimento das folhas o que pode ser explicado devido ao desenvolvimento desuniforme da dimensão da largura.

A área foliar em função dos dias após o plantio para o tomate se adequou a um modelo linear com $\mathrm{R}^{2}$ de no mínimo 91,41\% (Figura 5).

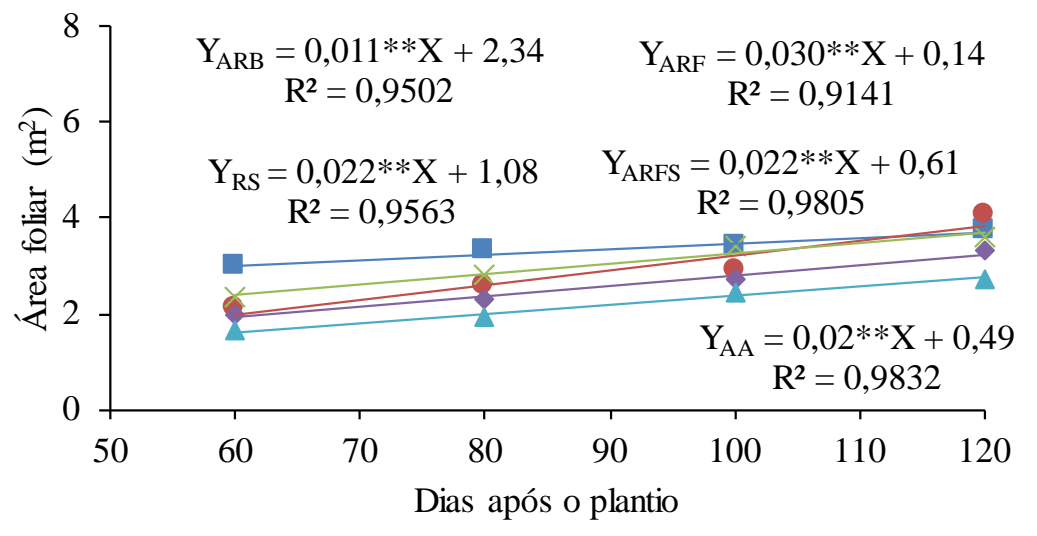

$\square \mathrm{ARB}-\mathrm{ARF} \times \mathrm{ARS} \bullet \mathrm{ARFS} \triangle \mathrm{AA}$

** $\mathrm{e}^{*}$ significativo respectivamente a $(\mathrm{p}<0,01$ e 0,05$)$ segundo teste $\mathrm{F}$.

Figura 5. Área foliar em função dos dias após o plantio para o tomate irrigado com água residuária bruta (ARB), água residuária filtrada (ARF), água residuária SODIS (ARS), água residuária 50\% filtrada 50\% SODIS (ARFS) e água de abastecimento (AA). 
Corroborando com estes resultados Brito et al. (2014) observaram adequação a um modelo linear da área foliar em função dos dias após o plantio com $\mathrm{R}^{2}$ de $88,11 \%$. A maior área foliar em tomate foi encontrada aos 120 dias após o plantio, sendo este 50,0; 18,33 ; 48,10; 35,40 e $40,57 \%$ maior do que os observados aos 60 dias após o plantio, para os tipos de água residuária bruta, filtrada, SODIS, $50 \%$ filtrada 50\% SODIS e de abastecimento, respectivamente; consequentemente, de acordo com a equação de regressão obteve o acréscimo de 16,66; 6,$11 ; 16,03 ; 11,80$ e $13,52 \%$ para cada aumento de 20 dias após o plantio para os tipos de água residuária bruta, filtrada, SODIS, $50 \%$ filtrada $50 \%$ SODIS e de abastecimento, respectivamente. Celedonio et al. (2016) verificaram que as dose de biofertilizante, na cultura da figueira, proporcionaram respostas diferenciadas das plantas em relação à área foliar a partir dos 60 DAP, promovendo aumento com as doses mais elevada.

$O$ índice SPAD em função dos dias após o plantio para o tomate se adequou a um modelo linear com $\mathrm{R}^{2}$ de no mínimo 96,13\% (Figura 6).

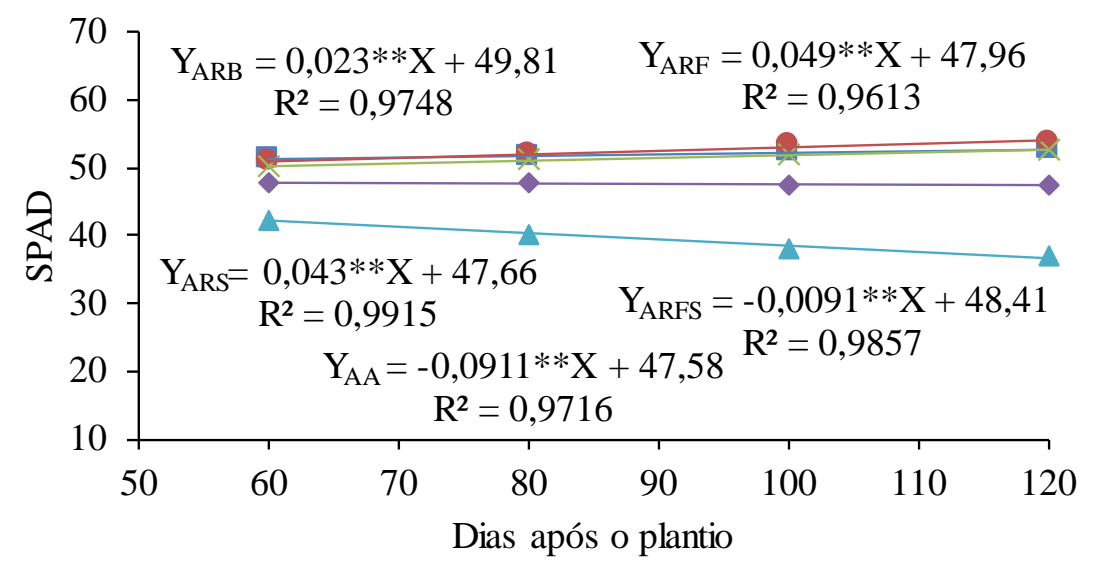

$\square \mathrm{ARB} \bullet \mathrm{ARF} \times \mathrm{ARS} \bullet \mathrm{ARFS} \triangle \mathrm{AA}$

** $\mathrm{e}^{*}$ significativo respectivamente a $(\mathrm{p}<0,01$ e 0,05$)$ segundo teste $\mathrm{F}$.

Figura 6. Índice SPAD em função dos dias após o plantio para o tomate irrigado com água residuária bruta (ARB), água residuária filtrada (ARF), água residuária SODIS (ARS), água residuária $50 \%$ filtrada $50 \%$ SODIS (ARFS) e água de abastecimento (AA).

O maior índice SPAD em tomate foi encontrado aos 120 dias após o plantio, sendo este 50,$0 ; 2,63 ; 5,49$ e $4,84 \%$ maior do que os observados aos 60 dias após o plantio, para os tipos de água residuária bruta, filtrada, SODIS e $50 \%$ filtrada $50 \%$ SODIS, respectivamente; consequentemente, de acordo com a equação de regressão obteve o acréscimo de 16,66; 0, 87; 1,83 e 1,61\% para cada aumento de 20 dias após o plantio para os tipos de água residuária bruta, filtrada, SODIS e $50 \%$ filtrada $50 \%$ SODIS, respectivamente. Na cultura do tomate, com a primeira aplicação do adubo, ocorreu o aumento do índice SPAD, já na segunda aplicação do adubo a eficiência foi menor, reduzindo os índices SPAD (REIS et al., 2013a).

Para o tipo de água de abastecimento, o maior índice SPAD em tomate foi encontrado aos 60 dias após o plantio, sendo este 12,98\% maior do que o observado aos 120 dias após o plantio; consequentemente, de acordo com a equação de regressão obteve o decréscimo de 4,36\% para cada aumento de 20 dias após o plantio. Souza (2009) verificou valores do índice SPAD aos 60 dias após o plantio inferiores ao encontrado nesse trabalho.

Não houve diferença significativa para a variável altura de planta do tomate entre os tipos de águas aplicadas aos 60 dias após o plantio. Aos 80 dias após o plantio a altura de 
planta do tomate verificada no tipo de água $50 \%$ filtrada $50 \%$ SODIS foi $14,24 \%$ maior do que a altura de planta observada no tipo de água de abastecimento. Em relação aos 100 dias após o plantio a altura de planta do tomate verificada no tipo de água bruta foi 10,66 e $15,52 \%$ maior do que a altura de planta observada no tipo de água 50\% filtrada $50 \%$ SODIS e de abastecimento, respectivamente. Nos 120 dias após o plantio a altura de planta do tomate verificada no tipo de água SODIS foi 8,39; 15,72 e 25,68\% maior do que a altura de planta observada no tipo de água filtrada, $50 \%$ filtrada $50 \%$ SODIS e de abastecimento, respectivamente (Tabela 3). Ferreira et al. (2005) trabalhando com água residuária também verificou que a mesma promoveu maior crescimento de plantas em relação à água de abastecimento.

Tabela 3. Médias da altura de planta (AP) e diâmetro de caule (DC) do tomate para água residuária bruta (ARB), água residuária filtrada (ARF), água residuária SODIS (ARS), água 50\% filtrada 50\% SODIS (ARFS) e água de abastecimento (AA).

\begin{tabular}{ccccccccc}
\hline & \multicolumn{9}{c}{$\mathrm{DAP}^{1}$} \\
\cline { 2 - 9 } Tipos de água & \multicolumn{9}{c}{ AP } & \multicolumn{7}{c}{ DC } \\
\cline { 2 - 9 } & 60 & 80 & 100 & 120 & 60 & 80 & 100 & 120 \\
\hline ARB & $0,68 \mathrm{a}$ & $1,20 \mathrm{ab}$ & $1,69 \mathrm{a}$ & $2,03 \mathrm{a}$ & $8,78 \mathrm{a}$ & $9,10 \mathrm{a}$ & $10,31 \mathrm{a}$ & $10,46 \mathrm{a}$ \\
ARF & $0,68 \mathrm{a}$ & $1,15 \mathrm{ab}$ & $1,55 \mathrm{abc}$ & $1,88 \mathrm{~b}$ & $7,50 \mathrm{~b}$ & $8,65 \mathrm{ab}$ & $9,13 \mathrm{~b}$ & $9,46 \mathrm{~b}$ \\
ARS & $0,64 \mathrm{a}$ & $1,22 \mathrm{a}$ & $1,61 \mathrm{ab}$ & $2,05 \mathrm{a}$ & $8,19 \mathrm{ab}$ & $8,20 \mathrm{~b}$ & $9,32 \mathrm{~b}$ & $10,53 \mathrm{a}$ \\
ARFS & $0,65 \mathrm{a}$ & $1,24 \mathrm{a}$ & $1,51 \mathrm{bc}$ & $1,73 \mathrm{c}$ & $7,53 \mathrm{~b}$ & $8,36 \mathrm{ab}$ & $9,39 \mathrm{~b}$ & $10,43 \mathrm{a}$ \\
AA & $0,61 \mathrm{a}$ & $1,06 \mathrm{~b}$ & $1,43 \mathrm{c}$ & $1,52 \mathrm{~d}$ & $7,87 \mathrm{~b}$ & $8,36 \mathrm{~b}$ & $9,26 \mathrm{~b}$ & $9,65 \mathrm{~b}$ \\
\hline
\end{tabular}

${ }^{1}$ Dias após o plantio (DAP); médias com a mesma letra minúscula na coluna não indica diferença significativa pelo teste Tukey, a 5\% de probabilidade.

O diâmetro de caule do tomate verificado no tipo de água bruta foi $14,66 \%$ maior do que o diâmetro de caule observado no tipo de água filtrada aos 60 dias após o plantio. Nos 80 dias após o plantio o diâmetro de caule do tomate verificado no tipo de água bruta foi 9,85\% maior do que o diâmetro de caule observado no tipo de água SODIS (Tabela 3). Aos 100 dias após o plantio o diâmetro de caule verificado no tipo de água bruta foi 15, 52\% maior do que o diâmetro de caule observado no tipo de água de abastecimento. Em relação aos 120 dias após o plantio o diâmetro de caule verificado no tipo de água SODIS foi $25,68 \%$ maior do que o diâmetro de caule observado no tipo de água de abastecimento. Pelissari et al. (2009) trabalhando com água residuária de suinocultura também observou efeito significativo para a variável diâmetro de planta, uma consequência dos altos teores de nitrogênio e fósforo presentes nesse tipo de água.

O comprimento de folhas do tomate verificado no tipo de água bruta foi 9,63 e $17,94 \%$ maior do que o comprimento de folhas observado nos tipos de águas $50 \%$ filtrada 50\% SODIS e de abastecimento aos 60 dias após o plantio, respectivamente (Tabela 4).

Tabela 4. Médias de comprimento de folhas (CF) e largura de folhas (LF) do tomate para água residuária bruta (ARB), água residuária filtrada (ARF), água residuária SODIS (ARS), água 50\% filtrada 50\% SODIS (ARFS) e água de abastecimento (AA).

\begin{tabular}{|c|c|c|c|c|c|c|c|c|}
\hline \multirow{3}{*}{$\begin{array}{c}\text { Tipos } \\
\text { de } \\
\text { água }\end{array}$} & \multicolumn{8}{|c|}{$\mathrm{DAP}^{1}$} \\
\hline & \multicolumn{4}{|c|}{$\mathrm{CF}$} & \multicolumn{4}{|c|}{ LF } \\
\hline & 60 & 80 & 100 & 120 & 60 & 80 & 100 & 120 \\
\hline ARB & $13,71 \mathrm{a}$ & $14,80 \mathrm{a}$ & $15,08 \mathrm{a}$ & $15,82 \mathrm{ab}$ & $7,51 \mathrm{a}$ & $7,75 \mathrm{a}$ & $7,77 \mathrm{a}$ & $8,10 \mathrm{ab}$ \\
\hline $\mathrm{ARF}$ & $12,53 \mathrm{~b}$ & $14,09 a b$ & $15,05 \mathrm{a}$ & 16,73 a & 5,85 bc & $6,33 \mathrm{c}$ & $6,63 \mathrm{~b}$ & 8,39 a \\
\hline ARS & $12,73 \mathrm{ab}$ & $14,05 \mathrm{ab}$ & $15,26 \mathrm{a}$ & 15,34 bc & $6,29 \mathrm{~b}$ & $6,95 \mathrm{~b}$ & 7,73 a & $8,03 a b$ \\
\hline
\end{tabular}




\begin{tabular}{ccccccccc} 
ARFS & $12,39 \mathrm{~b}$ & $13,71 \mathrm{~b}$ & $14,39 \mathrm{a}$ & $14,65 \mathrm{~cd}$ & $5,55 \mathrm{c}$ & $5,77 \mathrm{~d}$ & $6,55 \mathrm{~b}$ & $7,79 \mathrm{~b}$ \\
AA & $11,25 \mathrm{c}$ & $11,90 \mathrm{c}$ & $12,77 \mathrm{~b}$ & $13,85 \mathrm{~d}$ & $5,05 \mathrm{~d}$ & $5,54 \mathrm{~d}$ & $6,57 \mathrm{~b}$ & $6,79 \mathrm{c}$ \\
\hline
\end{tabular}

${ }^{1}$ Dias após o plantio (DAP); médias com a mesma letra minúscula na coluna não indica diferença significativa pelo teste Tukey, a 5\% de probabilidade.

O comprimento de folhas do tomate verificado no tipo de água bruta foi 7,36 e $19,59 \%$ maior do que o comprimento de folhas observado nos tipos de águas 50\% filtrada 50\% SODIS e de abastecimento aos 80 dias após o plantio, respectivamente. Aos 100 dias após o plantio, o comprimento de folhas verificado no tipo de água SODIS foi $16,32 \%$ maior do que o comprimento de folhas observado no tipo de água de abastecimento.

Em relação aos 120 dias após o plantio, o comprimento de folhas verificado no tipo de água filtrada foi 12,43 e 17,21\% maior do que o comprimento de folhas observado nos tipos de água $50 \%$ filtrada 50\% SODIS e de abastecimento, respectivamente (Tabela 4). Resultados semelhantes foram observados por Silva et al. (2013) que verificaram que plantas que receberam irrigação por água residuária apresentaram área foliar superior à aquelas irrigadas com água de abastecimento público.

A largura de folhas do tomate verificada no tipo de água bruta foi 22,10 e $32,75 \%$ maior do que a largura de folhas observada nos tipos de água filtrada e de abastecimento aos 60 dias após o plantio, respectivamente. Aos 80 dias após o plantio, a largura de folhas do tomate verificada no tipo de água bruta foi 18,28; 10,32 e 28,51\% maior do que a largura de folhas observadas nos tipos de água filtrada, SODIS e de abastecimento, respectivamente (Tabela 4). A largura de folhas do tomate verificada no tipo de água bruta foi $15,44 \%$ maior do que a largura de folhas observada no tipo de água de abastecimento aos 100 dias após o plantio. Em relação aos 120 dias após o plantio, a largura de folhas de tomate verificada no tipo de água filtrada foi 7,15 e 19,07\% maior do que a largura de folhas observadas nos tipos de águas $50 \%$ filtrada 50\% SODIS e de abastecimento, respectivamente. Corroborando com estes resultados Nascimento et al. (2015) observaram que as plantas irrigadas com água de abastecimento obtiveram menores valores de área foliar se comparadas com as plantas irrigadas com diferentes tipos de água residuária.

A área foliar do tomate verificada no tipo de água bruta foi 28,97 e 44,90\% maior do que a área foliar observada nos tipos de águas filtrada e de abastecimento aos 60 dias após o plantio, respectivamente. A área foliar do tomate verificada no tipo de água bruta foi 22,21 e 42,48\% maior do que a área foliar observada nos tipos de águas filtrada e de abastecimento aos 80 dias após o plantio, respectivamente (Tabela 5). O aumento da área foliar propicia um aumento na capacidade da planta de aproveitar a energia solar visando à realização da fotossíntese e, desta forma, pode ser utilizada para avaliar a produtividade (REIS et al., 2013b).

Tabela 5. Médias de área foliar (AF) e índice SPAD do tomate para água residuária bruta (ARB), água residuária filtrada (ARF), água residuária SODIS (ARS), água 50\% filtrada 50\% SODIS (ARFS) e água de abastecimento (AA).

\begin{tabular}{|c|c|c|c|c|c|c|c|c|}
\hline \multirow{3}{*}{$\begin{array}{l}\text { Tipos } \\
\text { de água }\end{array}$} & \multicolumn{8}{|c|}{$\mathrm{DAP}^{1}$} \\
\hline & \multicolumn{4}{|c|}{$\mathrm{AF}$} & \multicolumn{4}{|c|}{ SPAD } \\
\hline & 60 & 80 & 100 & 120 & 60 & 80 & 100 & 120 \\
\hline ARB & $2,99 \mathrm{a}$ & $3,33 \mathrm{a}$ & $3,40 \mathrm{a}$ & $3,72 \mathrm{~b}$ & $51,29 a$ & $51,54 \mathrm{ab}$ & $52,11 \mathrm{~b}$ & $52,64 \mathrm{~b}$ \\
\hline ARF & 2,12 bc & $2,59 \mathrm{bc}$ & $2,90 \mathrm{~b}$ & 4,08 a & 50,84 a & 51,84 a & 53,26 a & 53,65 a \\
\hline ARS & $2,33 \mathrm{~b}$ & $2,83 \mathrm{~b}$ & $3,42 \mathrm{a}$ & $3,58 \mathrm{bc}$ & $50,13 \mathrm{~b}$ & $51,14 \mathrm{~b}$ & $52,02 \mathrm{~b}$ & $52,68 \mathrm{~b}$ \\
\hline ARFS & $1,99 \mathrm{c}$ & $2,29 \mathrm{c}$ & $2,73 \mathrm{bc}$ & $3,31 \mathrm{c}$ & $47,88 \mathrm{c}$ & 47,70 с & $47,47 \mathrm{c}$ & $47,35 \mathrm{c}$ \\
\hline AA & $1,65 \mathrm{~d}$ & $1,91 \mathrm{~d}$ & $2,44 \mathrm{c}$ & $2,73 d$ & $42,32 \mathrm{~d}$ & $40,25 \mathrm{~d}$ & $37,92 \mathrm{~d}$ & $37,02 \mathrm{~d}$ \\
\hline
\end{tabular}

${ }^{1}$ Dias após o plantio (DAP); médias com a mesma letra minúscula na coluna não indica diferença significativa pelo teste Tukey, a 5\% de probabilidade. 
Aos 100 dias após o plantio, a área foliar do tomate verificada no tipo de água SODIS foi 20,19\% maior do que a área foliar observada no tipo de água 50\% filtrada 50\% SODIS. Aos 120 dias após o plantio, a área foliar do tomate verificada no tipo de água filtrada foi 12,08 e $33,11 \%$ maior do que a área foliar observada nos tipos de SODIS e de abastecimento, respectivamente (Tabela 5). Souza (2010) constatou uma superioridade da aplicação da água residuária em relação à testemunha, que foi proporcionada pelo incremento nos valores médios de área foliar e que possivelmente estes incrementos estão relacionados a liberação de nutrientes pela água residuária de suinocultura.

O índice SPAD do tomate verificado no tipo de água bruta foi 2,25; 6,65 e 17,49\% maior do que o índice SPAD observado nos tipos de água filtrada, SODIS, 50\% filtrada $50 \%$ SODIS e de abastecimento aos 60 dias após o plantio, respectivamente. Aos 80 dias após o plantio, o índice SPAD verificado no tipo de água filtrada foi 1,35; 7,99 e 22,37\% maior do que o índice SPAD observado nos tipos de água SODIS, 50\% filtrada 50\% SODIS e de abastecimento, respectivamente (Tabela 5). Aos 100 dias após o plantio, o índice SPAD verificado no tipo de água filtrada foi 2,31; 10,87 e 28,79\% maior do que o índice SPAD observado nos tipos de SODIS, $50 \%$ filtrada $50 \%$ SODIS e de abastecimento, respectivamente. Aos 120 dias após o plantio, o índice SPAD verificado no tipo de água filtrada foi 1,88; 11,74 e $30,99 \%$ maior do que o índice SPAD observado nos tipos de água bruta, 50\% filtrada 50\% SODIS e de abastecimento, respectivamente. Sousa (2015) trabalhando com a aplicação de resíduos orgânicos verificou que a unidade SPAD adequada é de 46,8 , valor este que foi superior ao observado no tratamento com água de abastecimento, enquanto nos tratamentos com água residuária bruta, água residuária filtrada, água SODIS e água residuária 50\% filtrada $50 \%$ SODIS, o índice SPAD foi superior ao encontrado por este autor, indicando o efeito positivo da água residuária na cultura do tomate.

\section{CONCLUSÃO}

A água residuária bruta proporciona maior incremento na altura de planta, diâmetro de caule, comprimento de folhas, largura de folhas, área foliar e índice SPAD para o tomate, seguida da água residuária SODIS, filtrada, $50 \%$ filtrada $50 \%$ SODIS e de abastecimento.

O tomate submetido a aplicação de água residuária bruta de suinocultura demonstra um incremento de até 31\% na clorofila (índice SPAD). As leituras do SPAD indicam o bom estado de $\mathrm{N}$ do tomate (variedade Santa Clara) promovido pela aplicação de água residuária de suinocultura assim bem como o seu adequado teor de clorofila.

\section{REFERÊNCIAS}

AGRIANUAL. Anuário da agricultura brasileira. São Paulo: FNP, 2009. 497p.

\section{BLANCO, F.F. Tolerância do pepino enxertado à salinidade em ambiente protegido e controle da salinização do solo. Piracicaba. 1999. 104 f. Dissertação (Mestrado) - Escola Superior de Agricultura "Luiz de Queiroz", Universidade de São Paulo.}

BRITO, C.F.B.; FONSECA, A.; BEBÉ, F.V.; SANTOS, L.G. Desenvolvimento inicial do milho submetido a doses de esterco bovino Initial development of maize subjected to cattle manure. Rev. Ver. de Agroec. e Desenv. Sustentável, v. 9, n. 3, p. 244 - 250, 2014.L

$\begin{array}{llr}\text { CELEDONIO, } & \text { C.A.; } & \text { MEDEIROS, } \\ \text { J.F.; VIANA, T.V.A.; } & \text { SARAIVA, } \\ \text { K.R.; LIMA, G.H.P. Área foliar } \\ \text { da figueira em três ambienter de } \\ \text { cultivo, sob fertirrigação de biofertilizante } \\ \text { bovino. }\end{array}$

Agricultura Irrigada, v. 10, n. 2, p. 586 597, 2016. 
FERREIRA, D.F. Sisvar: a computer statistical analysis system. Ciência e Agrotecnologia, Lavras, v. 35, n. 6, p. 10391042, 2001.

FERREIRA, M.M.M.; FERREIRA, G.B.; FONTES, P.C.R.; DANTAS, J.P. Índice SPAD e teor de clorofila no limbo foliar do tomateiro em função de doses de nitrogênio e da adubação orgânica, em duas épocas de cultivo. Revista Ceres, v. 53, p. 83-92, 2006.

FONSECA, V.A.; BEBÉ, F.V.; BRITO, C.F.B.; RAMOS, A.G. O Crescimento de plantas de sorgo em função de adubação fosfatada. Centro Científico Conhecer, Enciclopédia biosfera, v. 10, n. 19, p. 652662, 2014.

GALZERANO, L.; MALHEIROS, E.B.; RUGGIERI, A.C.; RAPOSO, E.; MORGADO, E.S.; CAPUTTI, G.P.; COSTA, J.P.R.; SILVA, W.L. Estimativa da área foliar do capim-xaraés por meio de medidas lineares. Scientia Plena v. 8, n. 2, 2012.

HOEK, V.D.; HASSAN, M.U.; ENSINK, J.H.J.; FEENSTRA, S.; RASCHID-SALLY, L.; MUNIR, S.; ASLAM, R.; ALIM, N.; HUSSAIN, R.; MATSUNO, Y. Urban wastewater: a valuable resource for agriculture. A case study from Horoonabad, Pakistan. Colombo, Sri Lanka: International Water Management Institute, p. 1-29, 2002.

NASCIMENTO, J.S.; FIDELES FILHO, J. Crescimento, produção e alterações químicas do solo em algodão irrigado com água de esgotos sanitários tratados. Revista Caatinga, Mossoró, v. 28, n. 2, p. 36-45, 2015.

PELISSARI, R.A.Z.; SAMPAIO, S.C.; GOMES, S.D.; CREPALLI, M.S. Lodo têxtil e água residuária da suinocultura na produção de mudas de Eucalyptus Grandis (W, Hill ex Maiden). Eng. Agríc., Jaboticabal, v. 29, n. 2, p. 288-300, 2009.
PORTO, J.S.; COSTA, R.Q.C.; REBOUÇAS, T.N.H.; LEMOS, O.L.; LUZ, J.M.Q.; AMORIM, Y.F. Índice SPAD e crescimento do tomateiro em função de diferentes fontes e doses de nitrogênio. Scientia Plena, v. 10, n. 11, 2014.

REIS, J.S.; ALVES, S.M.F.; JUNIOR, J.Á.; PESSOA, A.A.; SILVA, R.R. Determinação de zonas de manejo para adubação nitrogenada em lavoura de tomate industrial. Revista Agrotecnologia, Anápolis, GO, p. 68-84, 2013a.

REIS, L.S.; AZEVEDO, C.A.V.; ALBUQUERQUE, A.W.; JUNIOR, J.F.S. Índice de área foliar e produtividade do tomate sob condições de ambiente protegido. Revista Brasileira de Engenharia Agrícola e Ambiental, Campina Grande, v. 17, n. 4, p. 386-391, 2013b.

SILVA, L.V.B.D.; LIMA, V.L.A.; SILVA, V.N.B.; SOFIATTI, V.; PEREIRA, T.L.P. Torta de mamona residual e irrigação com efluente sobre crescimento e produção de algodoeiro herbáceo. Rev. Bras. de Eng. Agrícola e Ambiental, v. 17, n. 12, p. 12641270, 2013.

SILVA, N.F.; CUNHA, F.N.; OLIVEIRA, R.C.; MOURA, L.M.F.; MOURA, L.C.; TEIXEIRA, M.B. Crescimento da cana-deaçúcar sob aplicação de nitrogênio via gotejamento subsuperficial. Rev. Bras. de Agricultura Irrigada, v. 8, n. 1, p. 1-11, 2014.

SOUSA, A.A.T.C. Biochar de lodo de esgoto: efeitos no solo e na planta no cultivo de rabanete. Dissertação (Mestrado) - Universidade de Brasília, p. 1-63, 2015.

SOUZA, C.B.S. Produção de minitubérculos de batata semente básica em vaso e hidroponia, em função de doses de nitrogênio. Dissertação (Mestrado) Universidade Federal de Viçosa, p. 1-85, 2009. 
SOUZA, J.A.R.; MOREIRA, D.A.; SOUZA, J.A.R.; MOREIRA, D.A.; FERREIRA, P.A. Avaliação de frutos de tomate de mesa produzidos com efluente do COELHO,

D.F. Crescimento desenvolvimento de tomateiro tratamento primário da água residuária da suinocultura. Engenharia na Agricultura, v. 18, n. 3, p. 198-207, 2010. fertirrigado com água residuária da suinocultura. Comt. ed., v. 5, n. 2, 2010. 